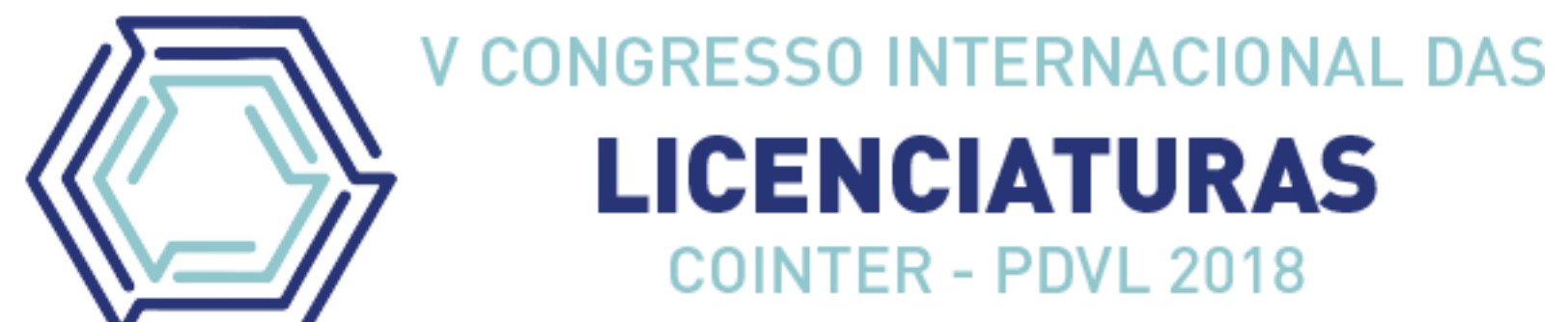

\title{
METODOLOGIAS ATIVAS: UM ESTUDO SOBRE AS CONCEPÇÕES DOS ESTUDANTES DE LICENCIATURA EM GEOGRAFIA NO IFPE
}

\section{ACTIVE METHODOLOGIES: A STUDY ON THE CONCEPTIONS OF GEOGRAPHIC STUDENTS IN GEOGRAPHY IN IFPE}

\author{
Apresentação: Comunicação Oral \\ Jacielly Tatiana da Silva Leocadio; Ana Paula Torres de Queiroz; Antônio Henrique do \\ Nascimento Filho; Claudia dos Santos Xavier; Jederson da Silva Rocha
}

DOI: https://doi.org/10.31692/2358-9728.VCOINTERPDVL.2018.00097

\begin{abstract}
Resumo: O presente artigo visa apresentar os conhecimentos dos estudantes do curso de licenciatura em geografia do IFPE, perante sua visão sobre metodologias ativas e se futuramente no chão da sala de aula eles irão utilizá-la. Ademais busca tratar as metodologias ativas como uma proposta para o ensino de geografia e compreender as concepções dos estudantes da licenciatura em geografia do IFPE acerca das metodologias ativas. Essas metodologias acarretam aulas inovadoras e dinâmicas, pois o professor deixa de ser o centro e a fonte da aprendizagem, para ser um mediador dela, proporcionando assim aos discentes a construção do conhecimento, além disso, contribui para deixar as aulas expositivas e interessantes e ao mesmo tempo auxilia no desempenho do docente. Para o desenvolvimento da pesquisa foi elaborada uma entrevista para aos discentes do Instituto Federal de Educação, Ciência e Tecnologia de Pernambuco (IFPE) Campus Recife, no qual foi voltado para os estudantes concluintes do $\left(7^{\circ}\right)$ sétimo período. De acordo com as respostas dos discentes, pode-se perceber que existem dois tipos perfis de estudantes, um conhece e utiliza e o outro conhece, mas discordam dessa prática. Chegamos à conclusão que nos dias atuais, é visível a presença do ensino tradicional na educação básica e as metodologias ativas surgem para quebrar esse paradigma, propondo uma forma diferente de ensino-aprendizagem que para uns são de grande valia, pois os auxilia a renovar as práticas docentes e trazer diversas dinâmicas ao se tratar do conteúdo abordado em sala. As consequiências vistas são idéias opostas sobre esse tema ao se tratar na sala de aula para os licenciandos, onde os professores de didática propõem essas técnicas para ajudá-los a se encontrar em sua prática profissional.
\end{abstract}

Palavras-Chave: Metodologias ativas; Ensino; Geografia 


\begin{abstract}
The present article aims to present the knowledge of the students of the undergraduate degree in geography of IFPE, before their vision on active methodologies and if in the future in the floor of the classroom they will use it. In addition it tries to treat the active methodologies as a proposal for the teaching of geography and to understand the conceptions of the students of the degree in geography of the IFPE about the active methodologies. These methodologies lead to innovative and dynamic classes, since the teacher ceases to be the center and source of learning, to be a mediator of it, thus providing students with the construction of knowledge, in addition, it contributes to leaving the classes interesting and interesting. at the same time assists in the performance of the teacher. For the development of the research, an interview was made for the students of the Federal Institute of Education, Science and Technology of Pernambuco (IFPE) Campus Recife, in which it was aimed at the final students of the (7th) seventh period. According to students' responses, it can be seen that there are two types of student profiles, one knows and uses and the other knows, but they disagree with this practice. We come to the conclusion that the presence of traditional teaching in basic education is visible today and the active methodologies emerge to break this paradigm, proposing a different form of teaching and learning that for some are of great value, as it helps them to renew the teaching practices and bring different dynamics when dealing with the content addressed in the classroom. The consequences are opposing ideas on this topic when dealing in the classroom for the graduates, where didactic teachers propose these techniques to help them find themselves in their professional practice.
\end{abstract}

Keywords: Active methodologies; Teaching; Geography

\title{
Introdução
}

O presente artigo busca abordar as metodologias ativas como uma proposta para o ensino de geografia e compreender as concepções dos estudantes da licenciatura em geografia do IFPE acerca das metodologias ativas.

. O interesse por esse tema surgiu por meio de debates no âmbito educacional, onde se observa nos dias atuais vários professores que utilizam o método tradicional que está presente desde meados do século XVIII, no qual o docente era considerado o detentor do saber, onde somente ele transmitia o conhecimento aos estudantes, vale ressaltar que o discente era ouvinte, não existia uma troca de saberes entre o professor e estudante, a função do mesmo se resumia em memorização, no qual se tratava de um recipiente, onde o professor "despejava" os conhecimentos. Nessa relação de informações era difícil para o professor identificar se algum estudante estaria aprendendo determinado conteúdo. No entanto, nos dias atuais com a disposição das tecnologias, favorece o aprendizado e o aperfeiçoamento na aula. A temática das metodologias ativas quebra o paradigma tradicional, de que o professor está no centro do processo de ensino e começa a visar os estudantes como o eixo e valorizar a importância de seus aprendizados. Há diversas formas de inovar na sala de aula, e as metodologias ativas 
favorecem para deixar as aulas expositivas interessantes para o estudante, fazendo com que facilite o seu aprendizado, e também o desempenho do professor quanto aos conteúdos ministrados

Historicamente o ensino brasileiro se pautou no paradigma tecnicista que fundamentou teoricamente a concepção de ensino tradicional. Essa concepção de ensino concebe o estudante como um depósito de conhecimento e o professor como o ser iluminado que deve ser o centro da produção de conhecimento na sala de aula. Essa concepção de ensino gerou inúmeras críticas ao sistema educacional e as práticas educativas, a partir dessas críticas surgiram possibilidades para uma nova forma de ensinar.

Uma das possibilidades é o uso de metodologias que façam do estudante sujeito ativo na produção de conhecimento na sala de aula. As metodologias ativas surgem como oposição ao ensino tradicional e possibilidade para que o ensino-aprendizagem possa ser significativo para os estudantes

A pesquisa fundamentou-se teoricamente nas contribuições de Breuren (2018) e Moran (2015) E teve na sua metodologia uma entrevista semi-estruturada com os estudantes do $7^{\circ}$ período da licenciatura em geografia do IFPE campus Recife.

\section{Fundamentação Teórica}

Breuren (2018) considera a geografia como um importante elemento curricular a ser explorado em sala de aula, pois esta disciplina permite que o estudante possa desenvolver a leitura do mundo em que vive. Nesse sentido, a geografia é uma disciplina que pode contribuir para a formação cidadã dos estudantes.

Breuren (2018) considera que essa concepção de ensino faz com que o conteúdo trabalhado em sala de aula seja distante da realidade do aluno, e assim os estudantes perdem o interesse pelas aulas de geografia.

Existem diversas discussões acerca das concepções de ensino de geografia, e a maioria é voltada para o âmbito da formação do docente de geografia, pois é na formação que o profissional tem contato com as concepções de ensino e se familiarizam com a que lhe melhor convêm.

A formação dos docentes, realizada no âmbito das universidades públicas brasileiras, foi marcada por uma forte presença do paradigma tecnicista de ensino, definida pela transmissão de modelos prontos e memorização de técnicas de ensino que deveriam ser 
fielmente seguidas no chão das escolas de educação básica. Além disto, os cursos de formação de professores organizavam- se com ênfase nos conteúdos específicos em detrimento dos conteúdos pedagógicos. Assim, por exemplo, a Licenciatura em Geografia formava muito mais o geógrafo, do que o professor de Geografia. A ênfase nesse modelo de formação está apoiada na habilitação para o domínio sobre os conteúdos tenderem a especialização dos saberes. (PIRES, 2009).

Porém a formação voltada apenas para os conteúdos pode abrir lacunas pedagógicas no professor formado, pois a carência de disciplinas pedagógicas pode prejudicar o profissional no âmbito metodológico.

Beuren (2018) destaca que é individualmente que o professor deve pensar suas praticas na sala de aula, pois apesar dos currículos e de sua formação, sua atuação é particular e cabe somente a ele conduzir suas aulas de forma que desperte o interesse dos estudantes.

As metodologias ativas são como uma possibilidade de ativar o aprendizado dos estudantes, colocando-os no centro do processo, em contraponto à posição de expectador. Com o intuito de uma maior interação do mesmo no processo de sua própria construção do conhecimento, nesta perspectiva o aprendiz passa a ter mais controle e participação efetiva na sala de aula, já que exige dele ações e construções mentais diversificadas, tais como: A leitura, pesquisa, observação, imaginação, organização dos dados entre outros.

Nas metodologias ativas de aprendizagem, o aprendizado se dá a partir de problemas e situações reais; os mesmos que os alunos vivenciarão depois na vida profissional, de forma antecipada, durante o curso. (MORAN, 2015)

As metodologias precisam acompanhar os objetivos solicitados. Se os professores querem que os estudantes sejam proativos, precisamos adotar metodologias que os alunos se envolvam em atividades cada vez mais complexas em que tenham que tomar decisões e avaliar os resultados, com apoio de materiais relevantes. Se os professores querem que os mesmos sejam criativos, eles precisam experimentar inúmeras novas possibilidades de mostrar sua iniciativa. (MORAN, 2015).

De acordo com o autor: 
Os jogos e as aulas roteirizadas com a linguagem de jogos cada vez estão mais presentes no cotidiano escolar. Para gerações acostumadas a jogar, a linguagem de desafios, recompensas, de competição e cooperação é atraente e fácil de perceber. Os jogos colaborativos e individuais, de competição e colaboração, de estratégia, com etapas e habilidades bem definidas se tornam cada vez mais presentes nas diversas áreas de conhecimento e níveis de ensino. (MORAN, 2015)

Silva e Cvalcanti (2008) consideram que atualmente a produção cultural pode ser um importante aliado no ensino escolar, pois vários conteúdos da escola podem ser melhor entendidos e internalizados a partir de obras literárias, artes, canções, peças, entre outros tipos de linguagens que fazem parte do dia-a-dia dos estudantes.

Alguns componentes são fundamentais para o sucesso da aprendizagem: A criação de desafios, atividades, jogos que realmente trazem as competências necessárias para cada etapa, que solicitam informações pertinentes, que oferecem recompensas estimulantes, que combinam percursos pessoais com participação significativa em grupos, que se inserem em plataformas adaptativas, que reconhecem cada aluno e ao mesmo tempo aprende com a interação, tudo isso utilizando as tecnologias adequadas. (MORAN, 2015)

Ensinar geografia pode ser considerado um desafio, pois fazer o estudante experimentar o espaço geográfico de forma abstrata é a missão do professor, nesse sentido o uso de metodologias ativas pode ser de grande valia em suas aulas, pois elas podem abrir a mente dos estudantes para reflexões em sala de aula.

\section{Metodologia}

A pesquisa elaborada é um estudo de caso de caráter qualitativo, ou seja, tenta entender a subjetividade do sujeito de pesquisa a partir do entendimento do significado do evento estudado para o sujeito.

O campo escolhido para a pesquisa foi o Instituto Federal de Educação, Ciência e Tecnologia de Pernambuco Campus Recife localizado na Avenida Professor Luís Freire, $\mathrm{N}^{\circ}$ 500, Bairro Cidade Universitária, Recife, Pernambuco. O Instituto é formado por Pesquisa, Ensino e Extensão, nele há uma diversidade de ensino, comportando estudantes do ensino de pós-graduação, superior e médio. 
Foi elaborado um questionário com o objetivo de compreender as concepções que os estudantes matriculados no último período de curso possuem acerca das metodologias ativas, e por meio da ferramenta Google Docs, que foi disponibilizada para os oito estudantes que estavam matriculados no componente curricular Estagio Supervisionado IV.

\section{Resultados e Discussão}

Os resultados obtidos através das entrevistas mostraram dois perfis de estudante, o primeiro compete aos que conhecem metodologias ativas e enxergam que elas são alternativas para melhorar o ensino de geografia; e o segundo perfil compete aos estudantes que conhecem as metodologias ativas, porém possuem resistência ao seu uso.

Aqui apresentamos uma discussão com o resultado das entrevistas, onde comparamos a posição de alguns estudantes com relação às metodologias ativas.

- Você acha que a utilização de metodologias ativas facilita aprendizado do conteúdo? Por quê?

E1- Sim, pois você permite que uma pessoa participe da construção do conteúdo de forma ativa, reflexiva e critica, faz com que o estudante se aproprie de tal conhecimento com maior facilidade.

E2- Acho que prejudica um pouco por tirar o protagonismo do professor, dificultando o trabalho em turmas onde os estudantes não tem muita autonomia para guiarem sua própria aprendizagem.

A partir da questão podemos perceber que entre os estudantes há diferentes concepções de ensino. Entre essas concepções podemos perceber a abordagem tradicional no E2. Essa concepção ainda persiste mesmo inúmeras renovações na ciência e na pedagogia. Essa concepção data dos primórdios da educação e acredita que o estudante é um deposito vazio (sem luz) e o professor (iluminado) deve depositar conhecimento. (MIZUKAMI, 1986)

Enquanto o E1 entende que a educação deve ser vista a partir de uma abordagem sociocultural. Esta escola entende que a educação deve ser promovida valorizando os sujeitos (estudantes) e a respeito dessa abordagem Mizukami (1986, p. 11) destaca que: "Toda ação 
educativa, para que seja válida, deve, necessariamente, ser precedida tanto de uma reflexão sobre o homem como de uma análise do meio de vida desse homem concreto, a quem se quer ajudar para que se eduque".

Outra pergunta realizada no questionário diz respeito a relação entre as metodologias ativas e a atenção dos estudantes.

- Quando você utiliza metodologias ativas, o interesse do aluno aumenta?

E4 - Bem, o interesse doo aluno geralmente aumenta, mas muitas vezes alguns alunos não estão interessados por alguns fatores externos à aula, porém de forma geral surtem um efeito positivo.

E-8 De modo geral o interesse dos estudantes aumenta sim, pois o conteúdo passa a ser mais interessante.

Sobre o interesse do estudante Cavalcanti (2002) considera que a utilização de outras linguagens (nesse caso as metodologias ativas) é essencial para se aproximar da realidade dos estudantes, pois abre a possibilidade para fazer a ponte entre o conhecimento cotidiano e o conhecimento cientifico.

Em seguida os estudantes são perguntados sobre a utilização de um recurso didático específico, que é considerado como uma metodologia ativa.

- Você já utilizou a música como recurso facilitador para o aprendizado de geografia? Justifique.

E1- Não, pois o conteúdo que já trabalhei não achei que seria pertinente do uso de tal instrumento didático.

E2- Já utilizei, não obtive o resultado esperado. 
E5- Nunca tive interesse de utilizar metodologias ativas.

Hallina Santos e Da Silva Coelho (2014), consideram a música como uma metodologia ativa, pois a música pode fazer o estudante escutar e refletir criticamente sobre sua realidade.

Ao considerar a música uma metodologia ativa o E2 planejou utiliza-la em sua sala de aula, porem o mesmo não conseguiu chamar a atenção da turma para o assunto. Podemos considerar que essa experiência negativa com a utilização de metodologias ativas possa ter modificado a forma que o E2 enxerga o ambiente escolar, criando nesta estudante simpatia pela concepção tradicional.

Enquanto o E1 e o E5 nunca utilizaram a música como metodologia em sala de aula, porém em outra questão o E1 pontua que acredita que acredita que as metodologias ativas podem ser facilitadoras do aprendizado.

As metodologias ativas são uma alternativa a monotonia que existe tradicionalmente nas salas de aula no Brasil, portanto devemos encorajar os professores e os formandos a utilizarem metodologias que considerem os estudantes como sujeitos ativos do conhecimento, de modo que os estudantes do ensino básico possam desenvolver senso crítico nas aulas de geografia, que eles possam se encontrar no mundo e entender o seu lugar no mundo.

\section{Conclusões}

O trabalho elaborado é voltado para compreender as concepções formuladas pelos estudantes a respeito das metodologias ativas, onde irá tratar também de um direcionamento à perspectiva de inovação na sala de aula, utilizando essas metodologias, pois faz com que o estudante se aproxime e despertem o interesse nas aulas expositivas. Pois ensinar não é transferir conhecimento, mas sim criar a possibilidade para que os estudantes possam produzir o conhecimento, portanto os saberes a serem estimulados na licenciatura devem estar alinhados com metodologias que possam criar o ambiente perfeito para o aprendizado.

No entanto ensinar geografia pode ser considerado um desafio, pois fazer o estudante experimentar o espaço geográfico de forma abstrata é a missão do professor, nesse sentido o 
uso de metodologias ativas pode ser de grande valia em suas aulas, pois elas podem abrir a mente dos estudantes para reflexões em sala de aula.

As metodologias ativas necessitam acompanhar os objetivos desejados. Se o docentes querem que os estudantes sejam proativos, precisam adotar métodos que os alunos se envolva com os exercícios cada vez mais complexos em que tenham que tomar decisões e avaliar os resultados, com o auxílio de materiais relevantes e autênticos. Se os professores querem que o discente seja criativo eles precisam experimentar inúmeras novas possibilidades de mostrar sua iniciativa.

Esperamos com este artigo mostrar novos horizontes, para o aprimoramento e melhorias das aulas, colaborando tanto com os estudantes, tanto com os professores. A busca por um bom ensino é constante e deve sempre ser atualizado fazendo com que o professor varie suas práticas e busque ser criativo e testar diversos mecanismos pedagógicos. Eles também devem desafiá-los a melhorar a cada dia através de novas estratégias entre outras contribuições. 


\section{Referências}

BEUREN, Elisabete Penz. Formação de professores de geografia à luz das metodologias ativas de ensino: desenvolvendo projetos interdisciplinares na Educação Básica. 2018. Dissertação de Mestrado.

CAVALCANTI, Lana de Souza. Geografia e práticas de ensino. Goiânia: Alternativa, 2002.

MIZUKAMI, Maria da Graça Nicoletti. Ensino: as abordagens do processo. Editora Pedagógica e Universitária, 1986.

MORAN, José Manuel. Mudando a educação com metodologias ativas. Coleção Mídias Contemporâneas. Convergências Midiáticas, Educação e Cidadania: aproximações jovens, v. $2,2015$.

SANTOS, H. COELHO,I. S. a música na sala de aula - a música como recurso didático. UnisantaHumanitas, v. 3, n. 1, p. 41-61, 2014

SILVA, Eunice Isaias da; CAVALCANTI, Lana de Souza. A mediação do ensinoaprendizagem de geografia, por charges, cartuns e tiras de quadrinhos. 2008. 